Universidade Tecnológica Federal do Paraná - UTFPR

Campus Ponta Grossa - Paraná - Brasil

ISSN: 1981-3686/ v. 9, n. 1: p. 1786-1796, 2015

D.o.I.: http://dx.doi.org/10.3895/rbta.v9n1.2001
Revista Brasileira de Tecnologia

Agroindustrial

\title{
AVALIAÇAO GRANULOMÉTRICA DE FRAÇOES CONSTITUINTES DE FARINHAS DE TRIGO TIPO 1 OBTIDAS DA MOAGEM INDUSTRIAL DE CULTIVARES DISPONÍVEIS NO MERCADO BRASILEIRO
}

\author{
Ricardo Barroso Lopes ${ }^{1}$, Ivo Mottin Demiate ${ }^{2}$ \\ ${ }^{1,2}$ Universidade Estadual de Ponta Grossa (UEPG), Programa de Pós-graduação em Ciência e \\ Tecnologia de Alimentos - Ponta Grossa PR - Brasil - ${ }^{1}$ ricolopes2001 @ yahoo.com.br; \\ 22demiate@yahoo.com
}

\begin{abstract}
Resumo
O objetivo deste estudo foi verificar algumas características físico-químicas de frações separadas por peneiração de quatro amostras de farinhas tipo 1, obtidas da moagem industrial de Triticum aestivum de cultivares utilizadas no Brasil, conhecidas como 'Quartzo', 'Supera' e 'Pardela'. O estudo avaliou também correlações entre as frações obtidas e os parâmetros de qualidade pesquisados. Também foram analisadas as curvas granulométricas das farinhas de cada variedade de trigo. Os resultados mostraram que existem significativas correlações entre granulometria e os parâmetros qualitativos analisados. Dentre essas correlações o percentual de amido danificado e a cor dos produtos em cada faixa granulométrica apresentaram elevados coeficientes, $r=-0,8651 e$ $r=-0,950$, respectivamente. $O$ estudo presente estudo permitiu concluir que a cultivar moída interfere na granulometria da farinha obtida industrialmente, e que este conhecimento é de grande importância para a compreensão das características físico-químicas dos produtos finais.
\end{abstract}

Palavras-chaves: farinha de trigo, granulometria, análises físico-químicas.

\section{Introdução}

O processo de produção de farinha de trigo branca é industrialmente realizado pela moagem deste cereal com emprego de equipamentos específicos que possibilitam a separação dos três principais constituintes do grão com a máxima eficiência em um processo mecânico de abertura do grão e sucessivos estágios de tamisações e novas moagens em bancos de cilindros até a obtenção do produto final. Diversas etapas de moagem (trituração ou quebra, compressão e redução), peneiramento (peneiradores planos ou peneiradores centrífugos) e, opcionalmente, a etapa de purificação (sassores) são associadas e sequenciais em moinhos especializados que operam com volumes variáveis de moagem diária, podendo superar 2.000 t. O produto obtido deve se enquadrar em normas estabelecidas e dentre as principais características a serem acompanhadas no processo de moagem, destacam-se o teor de cinzas e a cor, que deve ser muito clara (branca).

Posner (2008) define o processo industrial de moagem de trigo, como o desafio tecnológico de separação dos três principais componentes do grão, ou seja, do endosperma, do pericarpo e do embrião. Esta separação é especialmente complexa devido ao formato intrínseco do grão de trigo ( $\underline{\text { Triticum }} \underline{\text { aestivum }}$ e $\underline{\text { Triticum durum) }}$, devido a existência de um vinco na cariópse (crease, em 
inglês), e da camada de aleurona que apesar de ser parte constituinte do endosperma, não é facilmente integrada a fração amilácea do endosperma, que será reduzido a granulometria de farinha.

A legislação brasileira através da Instrução Normativa (IN) $\mathrm{n}^{\circ} 8$ do Ministério da Agricultura Pecuária e Abastecimento-MAPA, conforme "Regulamento Técnico de Identidade e Qualidade da Farinha de Trigo" (BRASIL, 2005) estipula que a farinha de trigo deve ter no máximo $15 \%$ de umidade, e classifica a farinha em Tipo 1, Tipo2 e Integral. Conforme a regulamentação o teor máximo de cinzas da farinha Tipo 1 não pode ultrapassar $0,800 \%$, enquanto nas farinhas Tipo 2 e Integral deve ser de, no máximo, 1,400 \% e 2,500 \%, respectivamente.

Dentre as características da farinha obtida em um processo de moagem, destacam-se aquelas relacionadas diretamente às suas aplicações. Aspectos reológicos e físico-químicos determinam a utilização da farinha de trigo. Dentre as características físico-químicas, a granulometria tem relevante importância na sua aplicação tecnológica, pois o tamanho das partículas constituintes da farinha interferirá em diversos parâmetros de qualidade, tais como na absorção de água da massa e no aspecto do produto final.

Wichser e Shellenberger (1950) realizaram pesquisas com diversas frações de farinhas

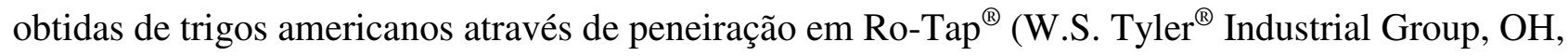
EUA) e analisaram as características destas frações a fim de determinar as principais características e propriedades reológicas e de cada uma delas. Verificaram também como a granulometria das farinhas analisadas interferia na produção de pães e bolos, bem como a relação destas frações com o teor proteico, a quantidade de amido danificado e o teor mineral.

Posner e Hibbs (2005) afirmam que o conhecimento da distribuição do tamanho das partículas constituintes da farinha, ou seja, da granulometria, é constantemente negligenciado por moleiros e panificadores. O conhecimento da distribuição granulométrica, entre outros parâmetros, garante a uniformidade da farinha. Segundo os autores, a distribuição do tamanho de partículas da farinha afeta o tempo de mistura dentro do processo de panificação e é responsável pela absorção de água, interferindo nas características de maquinabilidade da massa. Afirmam ainda, que no futuro os panificadores irão especificar a granulometria desejada para a farinha de forma mais acurada, para minimizar os efeitos destas variações na absorção de água e tolerância aos processos industriais de panificação.

Segundo Willm (2009) a granulometria de uma farinha de trigo depende antes de qualquer coisa da resistência mecânica do trigo no primeiro estágio de trituração, pois está relacionada à dureza do grão, mais ou menos alterada pela preparação da matéria-prima antes do início da moagem. Seu comportamento na moagem poderá se alterar em função da dureza do grão e das condições adotadas na etapa de condicionamento. $\mathrm{O}$ autor correlaciona também a dureza inicial do 
grão seco com o condicionamento do cereal antes da moagem e a umidade final da farinha obtida em um processo industrial.

Os resultados reportados no trabalho de Greffeuille et al. (2007), que estudaram cinco cultivares franceses representativos, duros e brandos, para panificação, mostraram que o caráter vítreo e a dureza dos grãos impactaram no comportamento do endosperma durante a moagem. A dureza influenciou principalmente a proporção de partículas pequenas (liberação de grânulos de amido do endosperma), enquanto o tamanho da semolina produzida na redução é influenciada principalmente pelo caráter vítreo, que pode, segundo os autores ser relacionado com o nível de porosidade. A caracterização de propriedades mecânicas intrínsecas do endosperma mostrou que a extensibilidade do endosperma de grãos vítreos foi maior quando comparada àquela de grãos farinosos (brandos) e estava associada à produção de partículas maiores.

Na moagem de Triticum aestivum, semolina é produzida na trituração e reduzida a farinha na compressão, sendo que farinhas das etapas de compressão e redução podem representar entre 30 e $40 \%$, respectivamente, do total de farinha da moagem (GREFFEUILLE et al., 2007).

Hrusková et al. (2006), estudando correlações entre parâmetros de moagem e a qualidade de panificação de 20 cultivares de trigo originados em 12 países, encontraram como as variáveis mais correlacionadas, a absorção de água e o rendimento em semolina $(\mathrm{r}=0,79)$. O volume de gás avaliado em fermentógrafo (Rheofermentometer ${ }^{\circledR}$, Chopin ${ }^{\circledR}$ Tripette \& Renaud, França) mostrou grande dependência do rendimento de semolina $(\mathrm{r}=0,89)$, da absorção de água avaliada em farinógrafo $(r=0,76)$ e da dureza dos grãos de trigo $(r=0,77)$. O volume específico dos pães foi mais afetado pelo conteúdo de proteína $(r=0,57)$, pelo rendimento de semolina $(r=0,57)$ e pelo volume de gás da fermentação $(r=0,61)$.

Maldonado e Rose (2013), em suas pesquisas com farinhas comerciais tipo integral, nos EUA, encontraram correlações entre granulometria das farinhas analisadas com o teor de cinzas, amido danificado, proteína e cor. Concluíram que este processo de fabricação não é padronizado nos EUA, mas que a distribuição granulométrica de uma farinha de trigo tem correlação com suas características e aplicações.

Choi e Baik (2013) pesquisaram a interferência da granulometria na qualidade de bolos obtidos da moagem de diversas cultivares de trigo. Os autores concluíram que aspectos granulométricos interferem na viscosidade da massa e também no volume do produto final. Gaines (1985), estudando 219 linhagens de trigos americanos brandos, concluíram que a obtenção de bolos com maiores volumes estava associada a farinhas com menores granulometrias, o que poderia estar associado a presença de maior proporção de amido danificado e também ao fato de partículas menores proporcionarem maior superfície com absorção de água superior o que geraria uma massa um pouco mais viscosa, favorecendo o crescimento dos bolos. O autor indica que a avaliação do 
tamanho de partículas de trigos brandos é muito importante para se prever a qualidade de bolos e cookies.

Gomez et al. (2010) destacam que o processo de moagem de trigo gera diferentes tipos de produtos (farinhas) que se distinguem em relação a granulometria, composição e funcionalidade quando empregados na produção de bolos. A granulometria, a composição e as propriedades de pasta de frações de farinhas (duas da quebra e três das etapas de redução) obtidas durante a moagem de três cultivares de trigo (baixo, médio e alto teor proteico) foram determinadas no trabalho destes autores. Na conclusão do trabalho, Gomez et al. (2010) destacaram que o tamanho de partículas de cada fração de farinha foi o parâmetro mais importante para a obtenção de bolos com melhores volumes e textura, sendo as farinhas com partículas menores as mais adequadas para esta aplicação tecnológica.

O objetivo deste estudo foi verificar algumas características físico-químicas de frações separadas por peneiração de quatro amostras de farinhas de trigo Tipo 1, obtidas da moagem industrial de Triticum aestivum de cultivares utilizadas no Brasil, conhecidas como 'Quartzo', 'Supera' e 'Pardela'. O estudo verificou também correlações entre as frações obtidas e características físico-químicas das farinhas, e também as curvas granulométricas das farinhas de cada uma das cultivares.

\section{Material e Métodos}

\section{Amostras de farinha}

As amostras de farinha inteira (todas as frações da moagem que compõem conjuntamente a farinha branca) foram obtidas em moinho industrial pela moagem das variedades 'Quartzo' (amostras 1 e 2 ), 'Pardela' e 'Supera'. O moinho industrial possuía as seguintes especificações técnicas: superfície de contato $9,00 \mathrm{~mm} / 100 \mathrm{~kg} / 24 \mathrm{~h}$, área de peneiração $0,050 \mathrm{~m}^{2} / 100 \mathrm{~kg} / 24 \mathrm{~h}$ e superfície de purificação $0,83 \mathrm{~mm} / 100 \mathrm{~kg} / 24 \mathrm{~h}$.

\section{Separação por tamisação}

As curvas granulométricas das farinhas inteiras foram avaliadas, utilizando-se a peneiração até peso constante em cada uma das peneiras sobrepostas em um peneirador RO-TAP ${ }^{\circledR}$ (Modelo RX-29-16; W.S.Tyler, OH, EUA). As telas utilizadas para classificações granulométricas foram: $180 \mu \mathrm{m}, 150 \mu \mathrm{m}, 125 \mu \mathrm{m}, 106 \mu \mathrm{m}$ e base (fundo). Devido a pequena retenção de produto nas telas de $150 \mu \mathrm{m}$ e $180 \mu \mathrm{m}$ estas frações foram desconsideradas na análise. Cada tamisação foi realizada com a farinha inteira e a separação das granulometrias foi feita na ordem decrescente das aberturas das telas. Utilizou-se o material peneirado em cada tela para realizar a tamisação posterior. Com os 
valores de produto retido em cada uma das telas foram construídas curvas granulométricas para cada cultivar de trigo pesquisado, correlacionando o percentual de material retido com a respectiva abertura da tela utilizada.

\section{Análises físico-químicas dos grãos e das farinhas obtidas}

As análises realizadas incluíram a determinação de umidade, proteína, dureza dos grãos (PSI), cinzas, peso de mil grãos, Falling Number, cor instrumental e nível de amido danificado.

O peso de mil grãos foi determinado considerando-se a massa de 1000 sementes sadias, livres de impurezas e materiais estranhos, realizada em equipamento NUMIGRAL 01 (Chopin, França) e a determinação da umidade dos grãos e das farinhas foi realizada utilizando-se uma Termobalança Brabender modelo HAV conforme metodologia 110/1 da AACC (2000). As análises de umidade foram realizadas em triplicata e os resultados foram utilizados para correção de umidade para base seca das análises de cinzas. Os teores de cinzas dos grãos e das farinhas de trigo foram determinados em forno mufla conforme metodologia 08-01 (AACC, 2000) e as análises foram realizadas em triplicata, com correção para a base seca. O teor de proteína das farinhas foi determinado por digestão ácida e destilação por arraste de vapor, pelo método de Kjeldahl, conforme metodologia 46-10 (AACC, 2000). Os valores de amido danificado nas farinhas foram determinados em triplicata, com o emprego do equipamento SD Matic (Chopin, França), conforme metodologia 76-30 (AACC, 2000). A cor instrumental de cada farinha retida nas respectivas telas foi analisada por intermédio de um Colorímetro Minolta modelo CR300, conforme metodologia 1430 (AACC, 2000). O único valor considerado neste trabalho foi o valor de L do equipamento, que representa a claridade/cor branca das amostras. A avaliação da dureza dos grãos de trigo (dureza PSI) foi realizada conforme metodologia 55-30 (AACC, 2000). Também se verificou a atividade enzimática da alfa-amilase dos grãos utilizados na pesquisa (Falling Number), conforme metodologia 56-81 B (AACC, 2000).

\section{Análise estatística}

Os dados foram analisados com o software STATDISK 11.1.0, verificando-se os desvios padrões das médias para cada análise e também para analisar as correlações entre as variáveis pesquisadas e as faixas granulométricas utilizadas no experimento. O intervalo de confiança utilizado nos experimentos foi de $95 \%(\mathrm{P}<0,05)$.

\section{Resultados e Discussão}

As cultivares de trigo analisadas apresentaram valores diferentes para atividade enzimática (Falling Number), teor de proteína, umidade e peso de mil grãos. Entretanto, por se tratarem de 
cultivares idênticos, esperava-se que as amostras 'Quartzo' 1 e 2 apresentassem valores semelhantes para estes parâmetros qualitativos. A Tabela 1 mostra que para peso de mil grãos e teor de proteína essas amostras apresentaram valores distintos, o que pode ter origem nas condições de cultivo e disponibilidade de nutrientes, pois fatores agronômicos podem interferir diretamente no processo de desenvolvimento da planta e consequentemente nas características dos grãos após a colheita (Franceschi et al., 2009).

As farinhas obtidas das moagens industriais apresentaram distribuições granulométricas distintas para cada cultivar de trigo (Figuras 1, 2 e 3). Isto se deve as características intrínsecas dos trigos, que se diferenciavam em dureza, o que demandou umidificação e tempo de descanso específico para cada um dos materiais, conforme resultados descritos por Greffeuille et al. (2007), que também identificaram comportamentos semelhantes para os cultivares franceses pesquisados.

As curvas granulométricas das cultivares 'Supera' e 'Pardela' produziram menor quantidade de produtos na faixa granulométrica $<106 \mu \mathrm{m}$, quando comparadas às cultivares QUARTZO (Tabela 3).

Por ser uma cultivar de trigo com grãos mais brandos (Tabela 2), o trigo 'Supera' apresentou maior dificuldade de tamisação, o que explica a produção de menores quantidades de frações mais finas (< $106 \mu \mathrm{m})$. Entretanto, o comportamento verificado para a cultivar 'Pardela' precisa de investigação complementar para possibilitar melhor compreensão do perfil granulométrico obtido. As cultivares 'Quartzo' (amostras 1 e 2) apresentaram perfis granulométricos semelhantes indicando que tiveram comportamentos similares durante o processo de moagem industrial. Esse esperado comportamento está relacionado aos mesmos tempos de descanso e condicionamento na etapa que antecedeu a moagem. De acordo com Posner e Hibbs (2005), o conhecimento da granulometria é fundamental para abastecimento estável do produto final, e as Figuras 1 a 3 mostram que dependendo da cultivar de trigo são obtidos perfis granulométricos distintos.

Acima desta faixa granulométrica não foram observadas diferenças significativas na classificação de farinha.

Tabela 1. Características dos trigos utilizados na moagem industrial, com médias de triplicatas e desvio padrão $(\mathrm{P}<0,05)$.

\begin{tabular}{lcccc}
\hline Cultivar & $\begin{array}{c}\text { Falling Number } \\
(\mathbf{s})\end{array}$ & $\begin{array}{c}\text { Proteína \% } \\
\text { (fator 5,7) }\end{array}$ & $\begin{array}{c}\text { Umidade } \\
(\boldsymbol{\%})\end{array}$ & $\begin{array}{c}\text { Peso de mil grãos } \\
(\mathbf{g})\end{array}$ \\
\hline 'Quartzo' (amostra 1) & $364+/-1,00$ & $10,0+/-0,10$ & $12,6+/-0,15$ & $34,14+/-0,076$ \\
'Quartzo' (amostra 2) & $357+/-3,61$ & $11,3+/-0,12$ & $11,3+/-0,15$ & $29,63+/-0,051$ \\
'Pardela' & $394+/-2,08$ & $10,5+/-0,13$ & $13,0+/-0,15$ & $32,28+/-0,020$ \\
'Supera' & $353+/-1,00$ & $12,7+/-0,14$ & $11,0+/-0,20$ & $30,97+/-0,036$ \\
\hline
\end{tabular}


Tabela 2. Características do trigo condicionado para moagem industrial, com médias de triplicatas e desvio padrão

$(\mathrm{P}<0,05)$

\begin{tabular}{lcccc}
\hline Trigo condicionado & Supera & Quartzo amostra 1 & Quartzo amostra 2 & Pardela \\
\hline Umidade & $13,8+/-0,02$ & $15,9+/-0,05$ & $15,7+/-0,02$ & $17,1+/-0,03$ \\
Dureza (PSI) & $22,6+/-0,14$ & $15,0+/-0,10$ & $15,5+/-0,11$ & $16,4+/-0,11$ \\
& 12 & 17 & 16 & 14 \\
\hline
\end{tabular}

Posteriormente foram realizadas curvas granulométricas com cada uma das farinhas obtidas com a finalidade de determinar o perfil granulométrico de cada uma delas. Este perfil serviu de definição para a separação das frações de cada uma das farinhas e posterior análise físico-química do material retido nas respectivas telas.

Tabela 3. Características das frações de farinha, com médias das triplicatas e desvio padrão $(\mathrm{P}<0,05)$.

\begin{tabular}{|c|c|c|c|c|c|}
\hline Farinha & $\%$ & $\begin{array}{c}\text { Cor } \\
\text { ( L Minolta ) } \\
\end{array}$ & $\begin{array}{c}\text { Umidade } \\
(\%) \\
\end{array}$ & $\begin{array}{c}\text { Cinzas } \\
(\% \text { base seca }) \\
\end{array}$ & $\begin{array}{c}\text { Amido Danificado } \\
(\%)\end{array}$ \\
\hline Inteira Supera & 100 & $93,1+/-0,046$ & $10,9+/-0,041$ & $0,620+/-0,008$ & $5,3+/-0,015$ \\
\hline$>125 \mu \mathrm{m}$ & 11,4 & $88,2+/-0,024$ & $10,8+/-0,024$ & $0,780+/-0,004$ & $3,4+/-0,116$ \\
\hline $125 \mu \mathrm{m}$ a $106 \mu \mathrm{m}$ & 81,2 & $93,4+/-0,041$ & $11,0+/-0,024$ & $0,565+/-0,004$ & $5,5+/-0,431$ \\
\hline$<106 \mu \mathrm{m}$ & 7,4 & $94,3+/-0,045$ & $10,3+/-0,028$ & $0,560+/-0,003$ & $6,2+/-0,375$ \\
\hline Inteira Pardela & 100 & $92,4+/-0,041$ & $13,3+/-0,081$ & $0,680+/-0,004$ & $6,7+/-0,010$ \\
\hline$>125 \mu \mathrm{m}$ & 13,9 & $88,4+/-0,043$ & $11,4+/-0,021$ & $0,606+/-0,010$ & $4,2+/-0,676$ \\
\hline $125 \mu \mathrm{m}$ a $106 \mu \mathrm{m}$ & 81 & $92,6+/-0,042$ & $11,6+/-0,082$ & $0,550+/-0,003$ & $7,0+/-0,066$ \\
\hline$<106 \mu \mathrm{m}$ & 5,1 & $93,7+/-0,045$ & $11,2+/-0,005$ & $0,665+/-0,001$ & $8,0+/-0,041$ \\
\hline Inteira Quartzo amostra 1 & 100 & $91,9+/-0,042$ & $13,05 /-0,022$ & $0,650+/-0,008$ & $7,5+/-0,010$ \\
\hline$>125 \mu \mathrm{m}$ & 15,4 & $88,8+/-0,042$ & $11,95+/-0,026$ & $0,515+/-0,027$ & $4,45+/-0,406$ \\
\hline $125 \mu \mathrm{m}$ a $106 \mu \mathrm{m}$ & 23,2 & $92,1+/-0,090$ & $11,5+/-0,016$ & $0,635+/-0,027$ & $7,3+/-0,462$ \\
\hline$<106 \mu \mathrm{m}$ & 61,4 & $93,1+/-0,045$ & $11,2+/-0,090$ & $0,800+/-0,006$ & $8,03+/-0,038$ \\
\hline Inteira Quartzo amostra 2 & 100 & $91,7+/-0,350$ & $12,9+/-0,037$ & $0,720+/-0,003$ & $7,36+/-0,030$ \\
\hline$>125 \mu \mathrm{m}$ & 14,3 & $88,8+/-0,032$ & $11,95+/-0,062$ & $1,200+/-0,033$ & $5,07+/-0,094$ \\
\hline $125 \mu \mathrm{m}$ a $106 \mu \mathrm{m}$ & 16,4 & $91,5+/-0,041$ & $11,2+/-0,250$ & $0,700+/-0,005$ & $7,27+/-0,020$ \\
\hline$<106 \mu \mathrm{m}$ & 69,3 & $92,7+/-0,041$ & $10,45+/-0,041$ & $0,685+/-0,006$ & $8,92+/-0,014$ \\
\hline
\end{tabular}


Figura 1. Curva Granulométrica das farinhas inteiras 'Quatzo’.

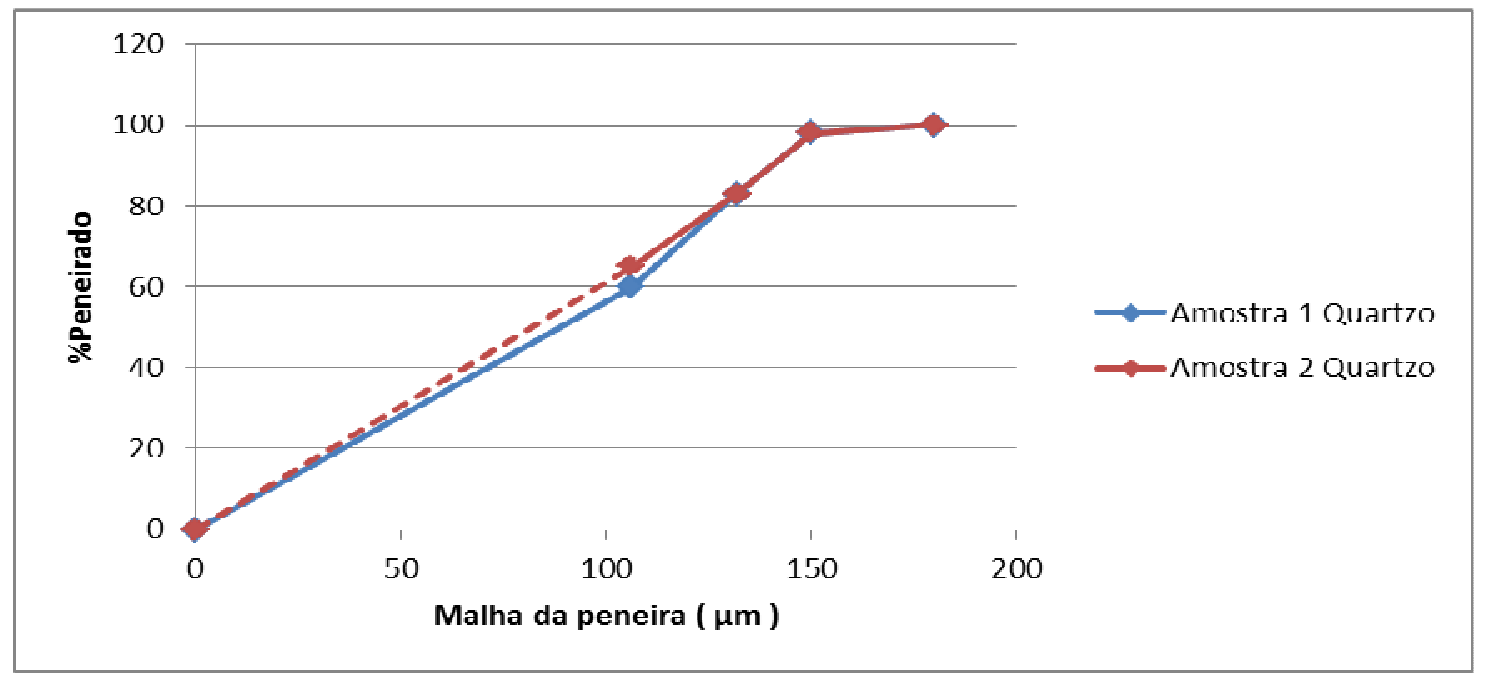

Figura 2. Curva Granulométrica farinha inteira 'Pardela'.

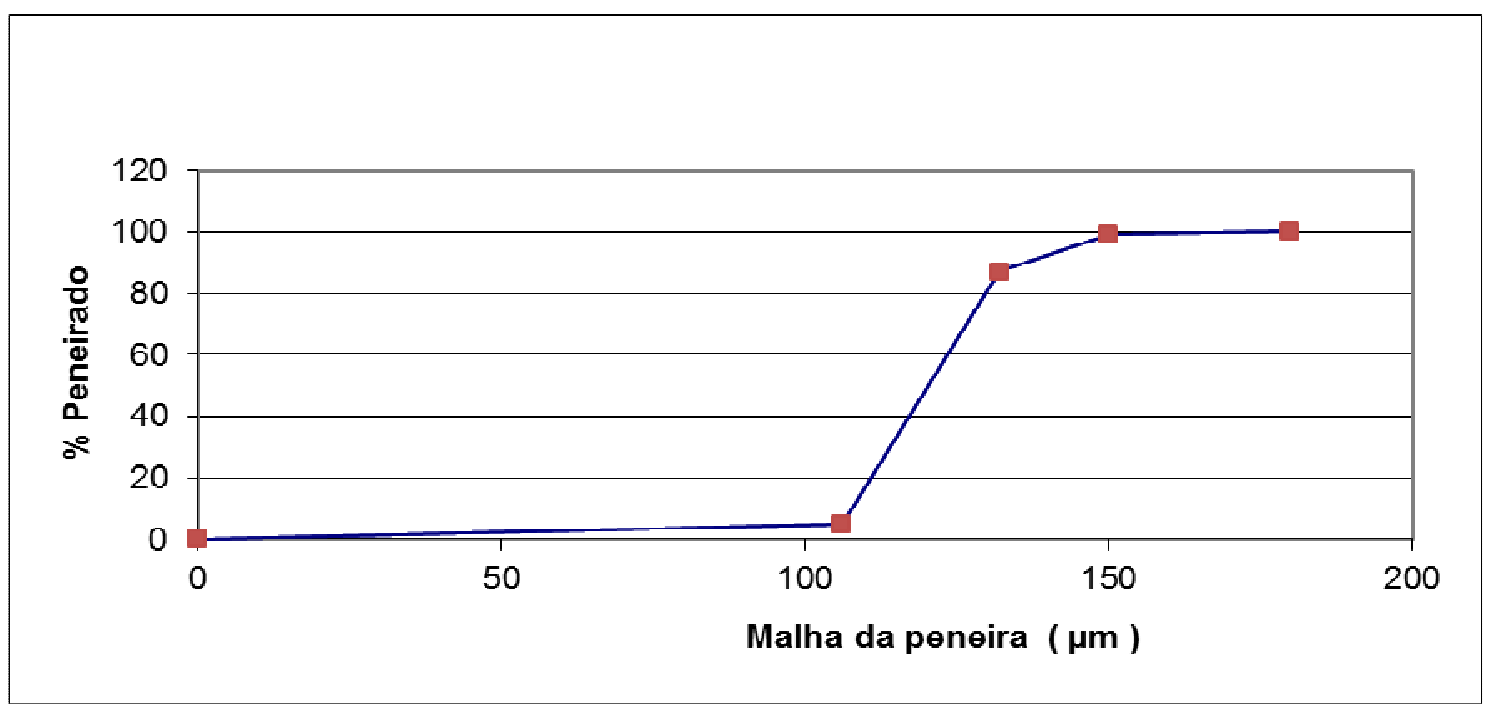

Figura 3. Curva Granulométrica farinha inteira 'Supera'.

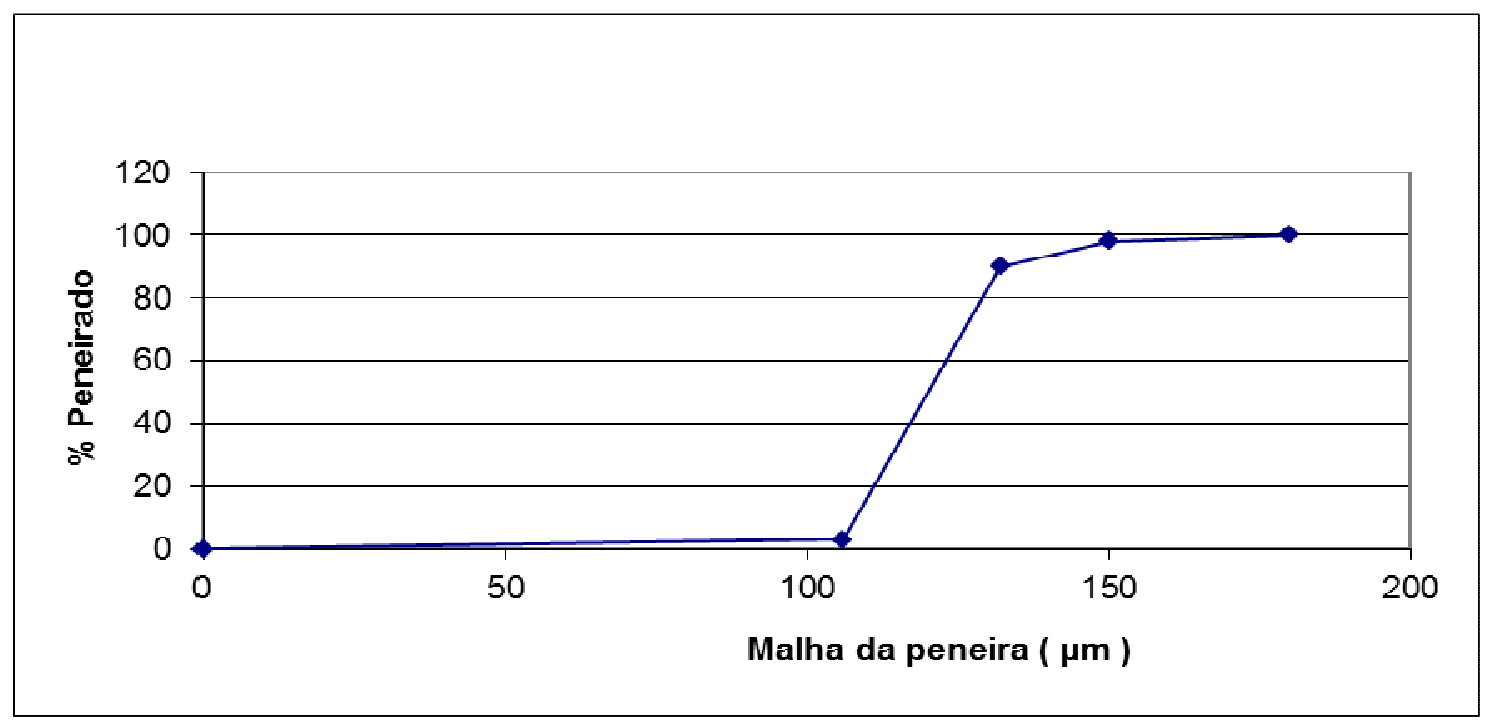


Os resultados revelaram que o percentual de amido danificado variou em cada faixa granulométrica, sendo que os menores valores foram encontrados nas maiores faixas granulométricas. O coeficiente de correlação entre a granulometria das frações retidas em cada tela e o teor de amido danificado foi de $\mathrm{r}=-0,8651(\mathrm{P}<0,05)$. No processo industrial a medida que se avança nos estágios intermediários de moagem, maior é o nível de danos ao amido e menor a disponibilidade de endosperma para ser reduzido a granulometria de farinha, obrigando que o processo reduza as aberturas das telas que realizam as tamisações de farinha a medida que este avanço ocorre no processo. Desta forma aumenta-se o nível de danos ao amido a medida que se reduz a faixa granulométrica, conforme constatado por Maldonado e Rose (2013) e por Wichser e Shellenberger (1950).

O teor de cinzas encontrado em cada fração apresentou baixa correlação com a granulometria das frações retidas. O coeficiente de correlação foi de $r=0,2408(\mathrm{P}<0,05)$. O teor de cinzas de cada farinha produzida na moagem do grão está relacionado com a região do grão de onde se obtém a farinha (POSNER e HIBBS, 2005). Farinhas oriundas de regiões externas do grão apresentam maior teor de minerais, e farinhas produzidas a partir da região mais central do grão apresentam menor teor de cinzas. Desta forma, é possível produzir farinhas das regiões mais externas do grão com aberturas granulométricas muito pequenas, e, portanto, estas frações apresentarão maior teor de minerais em sua composição, justificando a baixa correlação verificada entre teor de cinzas e as farinhas retidas em cada faixa granulométrica.

As cores verificadas em cada produto retido nas faixas granulométricas mostraram uma linearidade entre granulometria e o valor L. A correlação encontrada foi $\mathrm{r}=-0,930(\mathrm{P}<0,05)$ evidenciando que à proporção que a granulometria diminuiu, aumentou o valor de luminosidade (L). Assim como observado por Maldonado e Rose (2013), farinhas mais finas apresentam menor contaminação de fragmentação de fibras oriundas do farelo, e por essa razão apresentam maiores valores para L quando avaliadas com o colorímetro, indicando farinhas mais claras.

As cores dos produtos obtidos em cada faixa granulométrica apresentaram também boa correlação com os valores de amido danificado. A correlação encontrada foi de $\mathrm{r}=0,760(\mathrm{P}<0,05)$, da mesma forma que os resultados obtidos por Maldonado e Rose ( 2013 ) que observaram que farinhas mais finas apresentaram maiores valores de luminosidade (L) quando avaliadas em colorímetro, e estas farinhas apresentam maior quantidade de amido danificado mecanicamente.

\section{Conclusões}

A cultivar de trigo moído industrialmente interfere na granulometria da farinha obtida, e para minimizar esta variação, os controles de processo devem ser cuidadosamente ajustados para cada cultivar a ser moída. 
O conhecimento das frações granulométricas constituintes de uma farinha inteira é de grande importância para a compreensão das características físico-químicas do produto final, principalmente as variáveis que apresentaram correlação com granulometria.

Futuras pesquisas devem ser realizadas a fim de verificar se existem correlações entre granulometria e outros importantes parâmetros qualitativos da farinha, tais como a reologia.

\begin{abstract}
The aim of this study was to investigate some physicochemical characteristics of fractions separated by sieving of four samples of type 1 flour, obtained from industrial grinding Triticum aestivum of varieties used in Brazil, known as 'Quartzo', 'Supera' and 'Pardela'. The study evaluated also correlations between the fractions and the selected quality parameters. The size distribution curves of flours of each wheat variety were also analyzed. The results showed that there were significant correlations between the parameters of particle size and qualitative analysis. These correlations between the percentage of damaged starch and color of products in each particle size range showed higher coefficients, $r=-0.865$ and $r=-0.930$, respectively. The study concluded that the ground variety interferes with particle size of the flour obtained industrially, and that this knowledge is of great importance for understanding the physicochemical characteristics of the end products.
\end{abstract}

Key-words: wheat flour, granulation, physicochemical analyses.

\title{
Referências
}

AACC 2000, Approved Methods of American Association of Cereal Chemists.Methods tenth ed. American Association of Cereal Chemists, St.Paul, MN.

BRASIL. Ministério da Agricultura Pecuária e Abastecimento - MAPA, Trigo. Acesso em 24 de julho de 2014 , disponível em: http://www.agricultura.gov.br/vegetal/culturas/trigo

BRASIL. Ministério da Agricultura Pecuária e Abastecimento - MAPA, Instrução Normativa No 8 de 03/06/2005. Acesso em 24 de julho de 2014, disponível em: http://extranet.agricultura.gov.br/sislegisconsulta/consultarLegislacao.do?operacao=visualizar\&id=12214.

CHOI, H.W.; BAIK, B.K; Significance of Wheat Flour Particle Size on Sponge Cake Baking Quality. Cereal Chemistry Journal, v.90, p.150-156, 2013.

EDWARDS, N.; DEXTER, J. Alveograph Source of Problems in Curve Interpretation With Hard Common Wheat Flour. Canadian Institute of Food Science and Technology Journal, v. 20, p. 75-80, 1987.

FRANCESCHI, L. de; BENIN, G.; GUARIENTI, E.; MARCHIORO, V.S.; MARTIN, T.N. Fatores pré-colheita que afetam a qualidade tecnológica de trigo. Ciência Rural, v.39, n.5, p.1624-1631, 2009.

GAINES, C.S. Associations among soft wheat flour particle size, protein content, chlorine response, kernel hardness, milling quality, white layer cake volume, and sugar-snap cookie spread. Cereal Chemistry, v.62, n.4, p.290-292, 1985.

GOMEZ, M.; RUIZ-PARIS, E.; OLIETE, B. Influence of flour mill streams on cake quality. International Journal of Food Science and Technology, v. 45, p.1794-1800, 2010.

GREFFEUILLE, V.; ABECASSIS, J.; BAROUH, N.; VILLENEUVE, P.; MABILLE, F.; BAR L'HELGOUAC'H, C.; LULLIEN-PELLERIN, V. Analysis of the milling reduction of bread wheat farina: Physical and biochemical characterization. Journal of Cereal Science, v.45, p.97-105, 2007. 
HANSON, W.H. Granulation as a factor in Cake Flour. Association of Operative Millers. Technical Bulletins 1937 to 1943.

HRUSKOVÁ, M.; SVEC, I.; JIRSA, O. Correlation between milling and baking parameters of wheat varieties. Journal of Food Engineering, v.77, p. 439-444, 2006.

KHAN, K.; Shewry, P.R. Wheat Chemistry and Technology. Saint Paul : AACC, 4th ed., Chapter 3, 467p. 2008.

LOPES, R.B.; DEMIATE, I.M. Comportamento reológico e teste de panificação de farinha de trigo com diferentes granulometrias. In: Anais do XI Encontro Regional Sul de Ciência e Tecnologia de Alimentos (XI ERSCTA). Curitiba PR: SBCTA-PR, 2011. v. 1. p. 1-7.

MALDONADO,A.F.D;ROSE,D,J. Particle Distribution and Composition of Retail Whole Wheat FloursSeparated by Sieving. Cereal Chemistry, v.90, p.127-131, 2013.

POSNER, E.S.; HIBBS, A.N. Wheat Flour Milling. Saint Paul : AACC, 2nd ed. p.251-252, p.344-345, 2005.

SHELLENBERGER, J.A;WICHSER, F.W; LAKAMP.R.C.Cake Properties in Relation to Flour Particle Size Fractions. Flour Granulation Studies. The Millers' National Federation. Technical Report, April, 1950.

SHELLENBERGER, J.A; WICHSER, F.W; PENCE, R.O.A study of Flour Granulation. Flour Granulation Studies. The Millers'National Federation. Technical Report, April, 1950.

WICHSER, F.W.; SHELLENBERGER, J.A. Relationship of Physical Properties of Wheat Flour Granulation. Flour Granulation Studies. The Millers’' National Federation. Technical Report, April, 1950.

WICHSER, F.W.; SHELLENBERGER, J.A. Methods for Determining Flour Particle Size Distribution. Flour Granulation Studies. The Millers' National Federation. Technical report, April, 1950.

WILLM, C. La Mouture du Blé. Buenos Aires, Editions CEMP,Chapitre 11, p.240-242, 2009. 